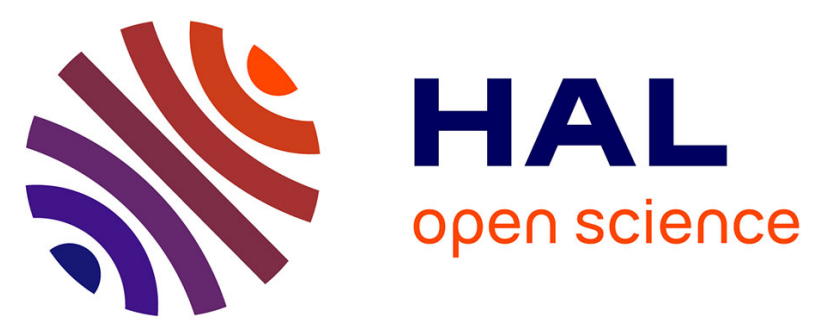

\title{
Intrusion-Extrusion of Electrolyte Aqueous Solutions in Pure Silica Chabazite by in Situ High Pressure Synchrotron X-ray Powder Diffraction
}

\author{
Giorgia Confalonieri, Andrey Ryzhikov, Rossella Arletti, Habiba Nouali, \\ Simona Quartieri, T. Jean Daou, Joël Patarin
}

\section{To cite this version:}

Giorgia Confalonieri, Andrey Ryzhikov, Rossella Arletti, Habiba Nouali, Simona Quartieri, et al.. Intrusion-Extrusion of Electrolyte Aqueous Solutions in Pure Silica Chabazite by in Situ High Pressure Synchrotron X-ray Powder Diffraction. Journal of Physical Chemistry C, 2018, 122 (49), pp.2800128012. 10.1021/acs.jpcc.8b07338 . hal-02413829

\author{
HAL Id: hal-02413829 \\ https://hal.science/hal-02413829
}

Submitted on 26 Jan 2022

HAL is a multi-disciplinary open access archive for the deposit and dissemination of scientific research documents, whether they are published or not. The documents may come from teaching and research institutions in France or abroad, or from public or private research centers.
L'archive ouverte pluridisciplinaire HAL, est destinée au dépôt et à la diffusion de documents scientifiques de niveau recherche, publiés ou non, émanant des établissements d'enseignement et de recherche français ou étrangers, des laboratoires publics ou privés. 


\title{
Intrusion-Extrusion of Electrolyte Aqueous Solutions in Pure Silica Chabazite by in situ High Pressure Synchrotron X-ray Powder Diffraction
}

\author{
Giorgia Confalonieria ${ }^{\mathrm{a}}$ Andrey Ryzhikov ${ }^{\mathrm{b}, \mathrm{c} *}$, Rossella Arlettia*, Habiba Nouali ${ }^{\mathrm{b}, \mathrm{c}}$, \\ Simona Quartierid ${ }^{d}, T$. Jean Daou ${ }^{b, c}$, Joël Patarin ${ }^{b, c}$
}

aDipartimento di Scienze della Terra, Università di Torino, Via Valperga Caluso 35, Torino, Italy

bUniversité de Haute Alsace (UHA), Axe Matériaux à Porosité Contrôlée (MPC), Institut de Science des Matériaux de Mulhouse (IS2M), UMR CNRS 7361, 3 bis rue Alfred Werner, F-68093 Mulhouse, France.

c Université de Strasbourg, Strasbourg, France

${ }^{d}$ Dipartimento di Scienze Matematiche e Informatiche, Scienze Fisiche e Scienze della Terra, Università di Messina, Viale Ferdinando Stagno d'Alcontres 31, 98166 Messina S. Agata, Italy

Corresponding Authors

Rossella Arletti

*E-mail: rossella.arletti@unito.it_Phone:+39 $0116705129 \quad$ Fax:+390116705128

Andrey Ryzhikov

E-mail: andrey.ryzhikov@uha.fr Phone: +33 $389336754 \quad$ Fax: +33 389608799 


\section{Abstract}

Structural investigation of the high pressure intrusion/extrusion of different electrolyte aqueous solutions ( $\mathrm{NaCl}, \mathrm{NaBr}$ and $\mathrm{CaCl}_{2}$ ) with different concentrations ( $2 \mathrm{M}$ and $\left.3 \mathrm{M}\right)$ in a pure-silica chabazite was carried out. In situ synchrotron X-ray powder diffraction experiments were performed in the pressure range of $0.12-2.6 \mathrm{GPa}$ and upon pressure release, in order to unravel the interactions among intruded species and host material. The energetic performance of the systems were determined by porosimetric studies. Results show that cation in the salt seems to influence the intrusion-extrusion pressures, whereas the structural evolutions, undergone by the systems upon pressure-induced intrusion, are essentially independent on the nature of the penetrating media. Moreover, the initial electrolyte concentration seems to influence only the value of the intrusion pressure, but neither the amount nor the interaction mode of the intruded species. Both water and salt molecules enter the pores and the penetration of comparable extra-framework volumes occurs at similar pressure values. However, the composition of intruded species is different from that of initial solution and depends on applied pressure that reinforces the hypothesis on ion desolvation under penetration into the pores. After pressure release, pure-silica chabazite intruded by $\mathrm{NaCl}$ and $\mathrm{NaBr}$ aqueous solutions does not recover the initial cell volume and partially retains the intruded extra-framework species. On the contrary, the zeosil intruded by $\mathrm{CaCl}_{2}$ recovers the original cell parameters. These differences have been structurally interpreted on the basis of the electrolyte/zeolite interactions. Interestingly, the extrusion behavior results to be mainly determined by the interactions of the anion with silanol defects of chabazite framework, rather than by the coordination bonds of the cation with the framework oxygen atoms.

\section{Introduction}

One of the promising technologies of mechanical energy absorption, storage and generation is based on forced penetration of a nonwetting liquid in porous solids ${ }^{1-10}$, where the energy of applied pressure is converted into the energy of solid-liquid interface. First "porous solid/nonwetting liquid" systems - called also heterogeneous lyophobic systems (HLS) - were developed by V. Eroshenko and co-workers on the base of porous silica ${ }^{1,2,11,12}$. Since 2001, pure-silica zeolites (zeosils) were proposed for this kind of application ${ }^{13}$. Since then, many zeosil-based heterogeneous lyophobic systems were studied ${ }^{14-24}$.Due to the presence of highly hydrophobic micropores with very small openings, these materials demonstrate high energetic performance under water intrusion, with 
intrusion pressures and stored energies up to $180 \mathrm{MPa}$ and $15 \mathrm{~J} / \mathrm{g}$, respectively ${ }^{17}$. Depending on the zeosil structure (pore system type, cage or channel, its dimensionality, size, presence of defects), the "zeosil/water" systems are able to restore, dissipate or absorb the supplied mechanical energy accumulated during the compression step that corresponds to a spring, shock absorber and bumper behavior, respectively.

The use of saline solutions instead of water was found to be an effective way to improve the energetic performance of heterogeneous lyophobic systems due to a considerable increase of intrusion pressure with salt concentration ${ }^{25-31}$. This increase is particularly pronounced in the case of zeosils, where a huge rise of intrusion pressure up to 7.4 times can be achieved for LTA-type zeosil using $\mathrm{LiCl}$ saturated solution (20 M) instead of water ${ }^{32}$. The highest ever stored energy value observed for zeosil-based heterogeneous lyophobic systems (93 J/g) shows the importance of using electrolyte solutions from a technology applicative point of view ${ }^{31}$.

Several hypotheses were proposed to explain this increase: (i) rise of liquid-solid interfacial tension ${ }^{33}$, confinement effect of nanopore walls ${ }^{34,} 35$, osmotic phenomenon ${ }^{36}$ and ion desolvation ${ }^{27}$. The last hypothesis, focusing on the distortion and desolvation of the water/ion system inside the micropores, seems to be the most pertinent, since the strong rise of intrusion pressure with electrolyte concentration cannot be explained by a simple increase of interface tension or osmotic phenomena ${ }^{36}$. The desolvation phenomenon was confirmed by our previous study on the intrusion of $\mathrm{MgCl}_{2}$ solution $\left(\mathrm{MgCl}_{2} \cdot 21 \mathrm{H}_{2} \mathrm{O}\right)$ in FER-type zeosil, performed by in situ X-ray powder diffraction (XRPD) under high pressure (HP). It was shown that the intruded liquid was neither water nor the initial diluted solution, but close to the saturated one $\left(\mathrm{MgCl}_{2} \cdot 10 \mathrm{H}_{2} \mathrm{O}\right)^{37}$.

The structural studies on the evolution of the zeosil systems under water or salt solution intrusion, and the analysis of the intruded species arrangement inside the pores are of great interest since they should allow to better understand, from an atomistic point of view, the mechanisms of intrusion-extrusion of electrolyte solutions in zeosils, which remain still unrevealed. The high potentialities of the structural studies, in particular by XRPD, on porous materials compressed with penetrating media have been clearly demonstrated by several investigations performed by many authors on a series of HP-induced phenomena (e.g. pressure-induced over-hydration, penetration, nanoconfinement and self-organization of guest molecules, pressure-induced deformations of the host matrix etc. $)^{38-42}$.

Understanding the behavior of confined species in these systems is extremely important for both technological applications (e.g. water desalination, ions and molecules separation, heterogeneous 
catalysis, adsorption, transport through biological membrane etc.) and advances in fundamental science.

In the present work, the HP intrusion-extrusion of electrolyte aqueous solutions $(\mathrm{NaCl}, \mathrm{NaBr}$ and $\mathrm{CaCl}_{2}$ at different concentrations) in a pure silica chabazite is studied by in situ synchrotron XRPD in order to unravel the nature and the location of the intruded species in zeosil pores. The results are compared with those obtained by intrusion-extrusion tests performed by porosimeter. The puresilica chabazite (CHA-type zeosil, Si-CHA from now on) was chosen because of its 3D pore system and relatively simple structure ( $R \overline{3} m$ space group). The framework can be described as an $A B C$ sequence of double 6-rings (D6R) of tetrahedra linked together through single 4-rings ${ }^{43}$. These building units define cages with high volume characterized by small 8MR (diameter of $0.38 \mathrm{~nm}$ ) pore openings. It should be noticed that the HLS based on Si-CHA showed earlier promising energetic performance under the intrusion-extrusion of $\mathrm{LiCl}$ aqueous solutions ${ }^{30}$.

\section{Experimental and Materials}

\subsection{Zeolite synthesis and characterization}

The Si-CHA sample was synthesized in fluoride medium according to the procedure described in the earlier works ${ }^{30,44}$. The N,N,N-trimethyladamantammonium (TMAda ${ }^{+}$) was used as a structuredirecting agent. The starting gel with molar composition $1 \mathrm{SiO}_{2}: 0.5 \mathrm{TMAdaOH}: 0.5 \mathrm{HF}: 4.7 \mathrm{H}_{2} \mathrm{O}$ was introduced in a Teflon-lined stainless-steel autoclave and heated at $150{ }^{\circ} \mathrm{C}$ for 5 days. After hydrothermal synthesis, the product was filtered, washed with distilled water and ethanol, and dried at $70{ }^{\circ} \mathrm{C}$ overnight. Then the solid was calcined at $600{ }^{\circ} \mathrm{C}$ for 8 hours to completely remove the organic template.

A $\mathrm{P}_{\mathrm{amb}}$ data collection at ambient pressure $\left(\mathrm{P}_{\mathrm{amb}}\right)$ on the synthesized material was carried out at XPRESS beamline at ELETTRA (Trieste, Itay) using a LaB $_{6}$ calibrated wavelength of $0.4957 \AA$. A structural refinement was performed starting from the coordinates taken from Diaz-Cabanas et al. $1998{ }^{44}$. The material resulted to be a pure $\mathrm{Si}-\mathrm{CHA}$ sample with a formula $\mathrm{Si}_{36} \mathrm{O}_{72}$. As a whole of 1.5 water molecules were located in the porosity before high pressure experiments (structural data are reported in SI). These data were taken as starting structural model for HP refinement.

\subsection{Porosimetric measurements with electrolyte solutions}


The intrusion-extrusion of water and aqueous salt solutions in Si-CHA was performed at room temperature using a Micromeritics mercury porosimeter (Model Autopore IV) in the range of 0.1$350 \mathrm{MPa}$. Before the measurements, the zeolite powder was compressed in a pellet. The cell containing zeosil pellet and electrolyte aqueous solution consists in a polypropylene cylinder of 2 $\mathrm{mL}$ capacity sealed using a mobile piston. This cell is introduced in the glass cell of the porosimeter, which is filled with mercury. The volume variation is determined from the capacity measurement, which depends on the height of mercury in the capillary tube of the glass cell. The experimental intrusion-extrusion curve is obtained after subtraction of the curve corresponding to the compressibility of the medium. Three intrusion-extrusion cycles (with measurement time of 1.5 hour per cycle) were performed. The values of the intrusion $\left(P_{\text {int }}\right)$ and extrusion $\left(P_{\text {ext }}\right)$ pressures correspond to that of the half volume total variation. Pressure is expressed in MPa, and volume variation in $\mathrm{mL}$ per gram of anhydrous calcined zeolite. The experimental error is of the order of $1 \%$ on the pressure and on the volume.

$2 \mathrm{M}$ and $3 \mathrm{M}$ aqueous solutions of $\mathrm{NaBr}, \mathrm{NaCl}$ and $\mathrm{CaCl}_{2}$ were used for intrusion-extrusion experiments, in order to study the influence of both cation $\left(\mathrm{Na}^{+}\right.$and $\left.\mathrm{Ca}^{2+}\right)$ and anion $\left(\mathrm{Br}^{-}\right.$and $\left.\mathrm{Cl}^{-}\right)$ nature. The concentrations were chosen to be sufficiently high in order to observe the influence of salt ions on the intrusion, but quite below the saturated ones, in order to avoid possible crystallization of the salts from solutions under HP. From now on, the "Si-CHA - salt aqueous solution" systems will be denoted shortly with the label "Si-CHA/Salt".

\subsection{High pressure synchrotron $X$-ray powder diffraction experiments}

HP in situ XRPD experiments were performed by means of modified Merril-Basser Diamond Anvil Cell ${ }^{45}$. Pressure was calibrated using the ruby fluorescence method ${ }^{46}$ on the non-linear hydrostatic pressure scale (estimated error is $0.05 \mathrm{GPa}$ ) ${ }^{47}$. As mentioned above, five different penetrating Pressure Transmitting Media (PTM) were used: $\mathrm{NaCl} 2 \mathrm{M}$ and $3 \mathrm{M}, \mathrm{NaBr} 2 \mathrm{M}$ and $\mathrm{CaCl}_{2} 2 \mathrm{M}$ and $3 \mathrm{M}$ aqueous solutions. The experiments with $3 \mathrm{M} \mathrm{NaBr}$ solution were not carried out since the salt crystallizes at low pressure. Measurements, in Debye Scherrer geometry, on "Si-CHA/NaCl" and "Si$\mathrm{CHA} / \mathrm{CaCl}_{2}$ " systems were done at SNBL1 (BM01) beamline at ESRF (Grenoble, France) with a fixed wavelength of $0.68202 \AA$. Diffraction intensities were collected by Pilatus IP detectors (with pixel dimensions of $172 \times 172 \mu \mathrm{m}$ ) positioned at a fixed distance of $239 \mathrm{~mm}$. The exposure time for each image was of 30 and $60 \mathrm{~s}$ for " $\mathrm{Si}-\mathrm{CHA} / \mathrm{NaCl}$ " and " $\mathrm{Si}-\mathrm{CHA} / \mathrm{CaCl}_{2}$ " systems, respectively. Data, on the "Si-CHA/NaBr" system, was obtained at BLO4-MSPD beamline at Alba (Barcelona, Spain) by CCD 
camera, SX165 (Rayonix). Wavelength was set at $0.5340 \AA$ and sample-detector distance was 160 $\mathrm{mm}$. Each point collection lasted $50 \mathrm{~s}$. Each collection was preceded by about 15 minutes of pressure stabilization. The powder patterns of the five systems were collected in the pressure ranges ( $P$ ranges) reported in Table 1 and after pressure release at ambient conditions. Diffraction images were integrated and treated obtaining one-dimensional patterns using Dioptas program ${ }^{48}$.

Table 1: Data collection pressures for the investigated systems

\begin{tabular}{lcc}
\hline System & P range (GPa) & P of salt crystallization (GPa) \\
\hline $\mathrm{Si}-\mathrm{CHA} / \mathrm{NaCl} 2 \mathrm{M}$ & $\mathrm{Pamb}-2.91$ & 2.91 \\
$\mathrm{Si}-\mathrm{CHA} / \mathrm{NaCl} 3 \mathrm{M}$ & $\mathrm{Pamb}-1.98$ & \\
$\mathrm{Si}-\mathrm{CHA} / \mathrm{NaBr} 2 \mathrm{M}$ & $\mathrm{Pamb}-3.45$ & 3.45 \\
$\mathrm{Si}-\mathrm{CHA} / \mathrm{CaCl}_{2} 2 \mathrm{M}$ & $\mathrm{Pamb}^{2}-1.07$ & 1.07 \\
$\mathrm{Si}-\mathrm{CHA} / \mathrm{CaCl}_{2} 3 \mathrm{M}$ & $\mathrm{Pamb}^{2}-1.29$ & \\
\end{tabular}

\subsection{Rietveld structure refinements}

Structure refinements were performed by means of Rietveld method using GSAS package ${ }^{49}$ with the EXPGUI ${ }^{50}$ interface. No phase transitions were observed under compression in the investigated systems, therefore profile fitting was carried out using the original $R \overline{3} m$ (hexagonal axes) space group. Cell parameters were determined up to 1.83, 2.16 and $0.82 \mathrm{GPa}$ for "Si-CHA/NaCl", "Si$\mathrm{CHA} / \mathrm{NaBr}$ " and "Si-CHA/CaCl 2 " systems, respectively. However, the limited data quality of the patterns collected at HP allowed performing the structural investigations only up to $1.21,0.96$ and $0.82 \mathrm{GPa}$, respectively. Data were fitted refining 2 theta-shift, scale and unit cell parameters. A Chebyshev polynomial with 30 coefficients was applied to refine the background, while Thomson pseudo-Voigt function ${ }^{51}$ was used for the peak profile, setting the peak cut-off as $0.1 \%$ of the peak maximum. The initial atomic framework coordinates were taken from the Pamb capillary data collection. In all the refinements the framework coordinates were refined imposing soft-restraints to the $\mathrm{Si}-\mathrm{O}$ distances $(1.60 \AA$ ) and gradually decreasing their weight (up to 10) after the initial stages. The Fourier Difference Map of the electronic density was inspected in order to locate the intruded extra-framework species. The position and the chemical nature of the intruded atoms were carefully defined taking into account the bond distances and mutually exclusion rules ${ }^{37}$. The interactions between anion-cation, anion-water, cation-water, water-water and the interactions of all the extra- 
framework species with the framework were then monitored during the refinements. Isotropic thermal parameters were forced to be equal for all the framework oxygen atoms; identical constraints were applied to the extra-framework atoms belonging to the same chemical species. Selected examples of observed and calculated profiles are shown in the Supporting Information (Figure S4-S13), where some refined structures are reported, as well.

\subsection{Other characterizations}

Si-CHA sample was characterized before and after intrusion-extrusion experiments with $2 \mathrm{M} \mathrm{NaBr}$ solution by thermogravimetric analysis, nitrogen adsorption-desorption and ${ }^{29} \mathrm{Si}$ solid-state NMR spectroscopy. The description and the results of these characterization methods are reported in Supporting Information.

\section{Results}

\subsection{X-ray diffraction results}

\subsubsection{Cell parameters dependence on pressure}

The unit cell parameter values derived from the experiments performed intruding Si-CHA with 2M or $3 \mathrm{M}$ solutions of the salts are reported in Table S35 in the supporting information. The inspection of the Tables indicates that the evolution of the unit cell parameters upon intrusion-extrusion is almost independent on the solution concentration. Therefore, in the following, only the structural data obtained using $2 \mathrm{M}$ electrolyte solutions will be discussed.

The evolution of Si-CHA cell parameters as a function of pressure for the investigated systems are reported in Figure 1 (as normalized values). For all the systems, the cell parameters were measured also upon pressure release to ambient conditions (labeled from now on as $\mathrm{P}_{\text {amb }}(\mathrm{rev})$ ). 

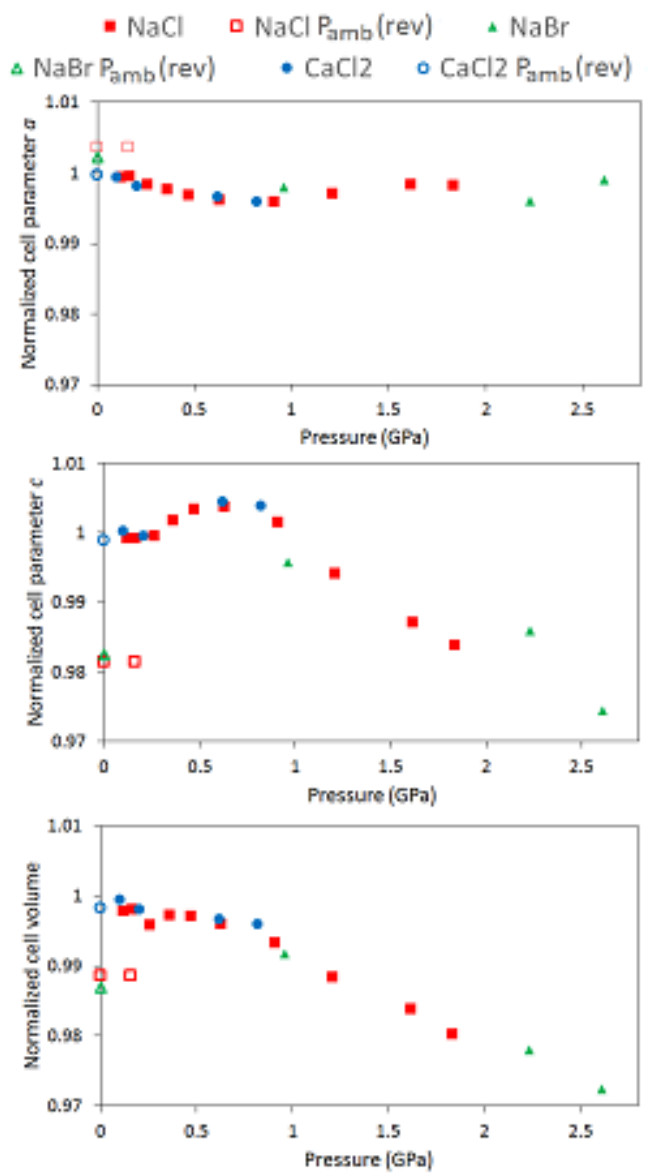

Figure 1: Evolution upon pressure of the normalized cell parameters of the investigated systems during the intrusionextrusion process (full symbols: values obtained during the intrusion process, open symbols: refer to the cell parameter values measured upon decompression to ambient conditions $\mathrm{P}_{\mathrm{amb}}(\mathrm{rev})$ ). All the data are relative to the $2 \mathrm{M}$ electrolyte solutions.

Regardless from the composition of the penetrating electrolyte solution, the evolution of the cell parameters with pressure shows common trends. In particular, from Figure 1 and Table 2, the following main steps are recognizable:

1) From $\mathrm{Pamb}_{\mathrm{amb}}$ to $0.20 \mathrm{GPa}$, cell volume displays a very small decrease.

2) Upon rising pressure up to $\sim 0.6 \mathrm{GPa}, c$ increases $(0.45 \%$ with respect to the ambient conditions). Since the $c$ increase is associated to a small $a$ reduction, the unit cell volume slightly decreases or remains almost constant.

3) These trends completely change in the range $0.63<\mathrm{P}<2.61 \mathrm{GPa}$ : a cell volume reduction is observed due to a strong $c$ decrease (coupled with an only slight $a$ increase).

4) Conversely to the intrusion process, the three systems have different behaviors upon pressure release. While "Si-CHA/CaCl 2 "system completely regains the initial unit cell parameters, "Si-CHA/NaCl" and "Si-CHA/NaBr" systems do not recover the original unit cell 
volume. In both cases, this is due to $c$ parameter, which does not regain its original value remaining shorter.

\subsubsection{Structural features of the "Si-CHA/NaCl" system}

The main finding of our experiments is that the application of pressure induces the penetration of both water molecules and $\mathrm{Na}^{+}$and $\mathrm{Cl}^{-}$ions inside Si-CHA structure. Figure 2 and Table 3 report the number of the intruded molecules per $\mathrm{Si}-\mathrm{CHA}$ unit cell $\left(36 \mathrm{SiO}_{2}\right)$ as a function of pressure. In addition, Figure 2 shows the decrease of the available accessible volume starting from the ambient value of $17.27 \%$ of Si-CHA accessible volume ${ }^{52}$. The overall intruded volume was calculated taking into account the number of the absorbed species (water molecules and ions) and their volumes. Specifically, in all the three systems, the ionic radii and the kinetics radii were respectively considered for ions and waters molecules volume calculation ${ }^{53}\left(\mathrm{~V}_{\mathrm{Na}}=4.06 \AA^{3}, \mathrm{~V}_{\mathrm{Cl}}=24.83 \AA^{3}\right.$, $\left.V_{\text {Water }}=9.7 \AA^{3}\right)$.

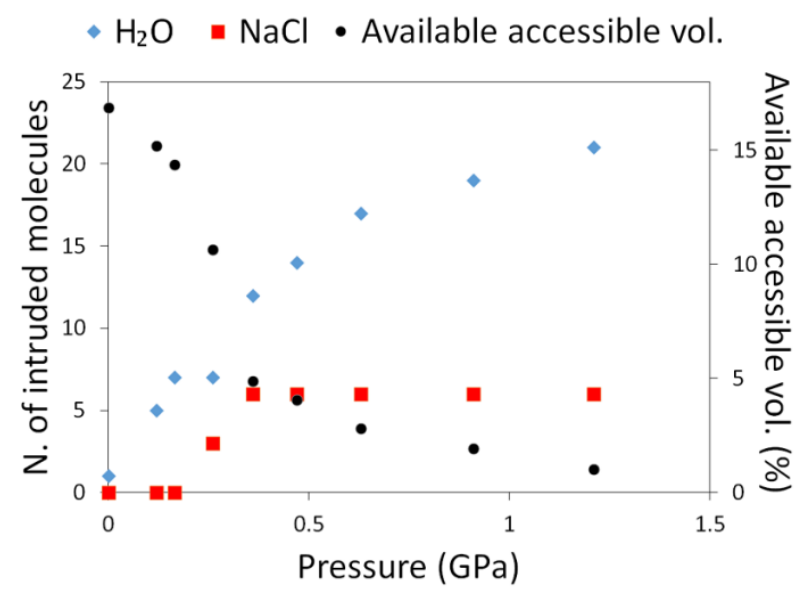

Figure 2: Extra-framework unit cell content (in terms of number of intruded molecules) and available accessible volume as a function of pressure during the intrusion process in the " $\mathrm{Si}-\mathrm{CHA} / \mathrm{NaCl} 2 \mathrm{M}$ " system. 

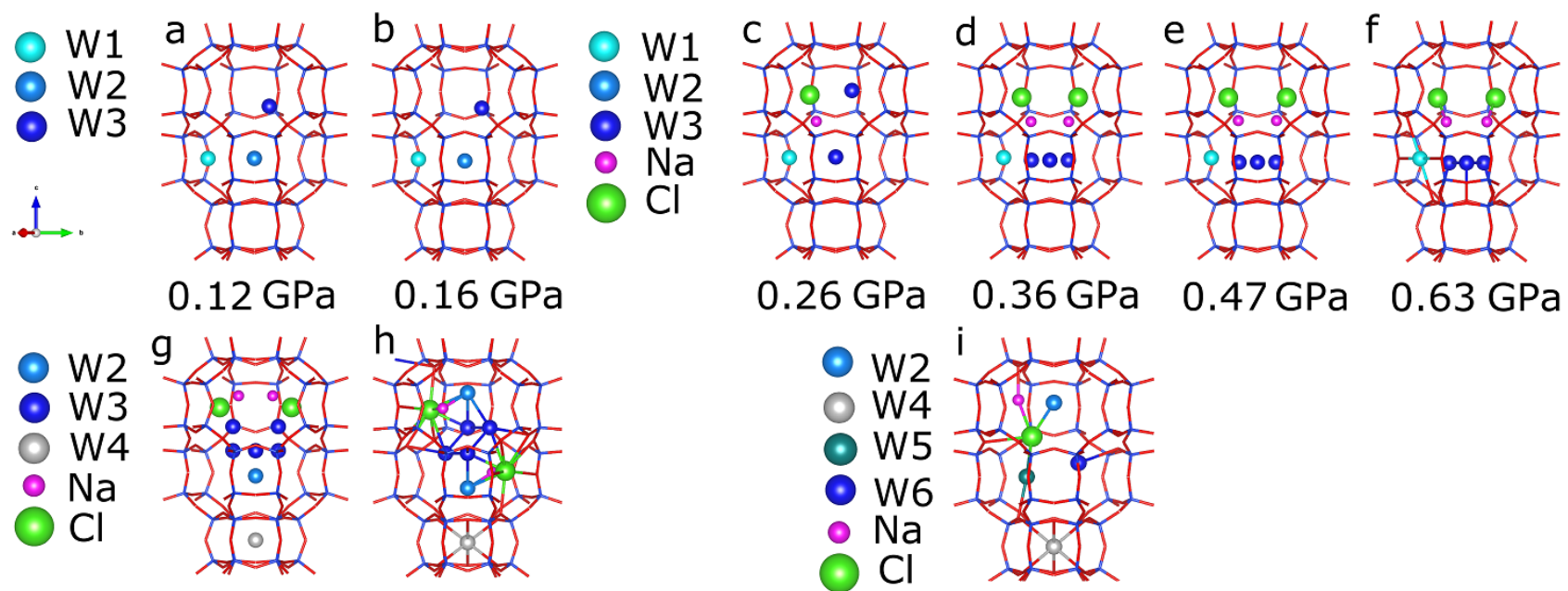

$0.36 \mathrm{GPa}$

$0.47 \mathrm{GPa}$

$0.63 \mathrm{GPa}$

$-\mathrm{w} 2$
$\div \mathrm{W} 3$
$\mathrm{~W} 4$
$\circ \mathrm{Na}$
$\mathrm{Cl}$
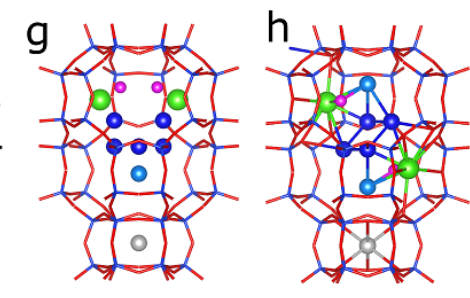

$0.91 \mathrm{GPa}$

$1.21 \mathrm{GPa}$

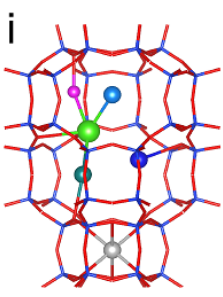

$P_{a m b}($ rev.)

Figure 3: Structural evolution of the extra-framework sites as a function of the pressure during the intrusion-extrusion process of $2 \mathrm{M} \mathrm{NaCl}$ aqueous solution in Si-CHA. Bond distances are drawn only for the structure of the highest pressure and after pressure release.

Table 3: Number of salt/water molecules hosted in Si-CHA unit cell as function of pressure during the intrusion-extrusion process in the "Si-CHA/NaCl $2 \mathrm{M}$ " system.

\begin{tabular}{llllllll}
\hline Pressure (GPa) & W1 & W2 & W3 & W4 & W5 & W6 & NaCl \\
\hline 0.12 & 1.3 & 0.6 & 3.1 & & & \\
0.16 & 1.9 & 1 & 4.3 & & & \\
0.26 & 2.6 & & 5 & & & 3 \\
0.36 & 3.4 & & 8.5 & & & 6 \\
0.47 & 4.2 & & 10.1 & & & 6 \\
0.63 & 5.1 & & 11.7 & & & 6 \\
0.91 & & 2.6 & 16.2 & 0.12 & & 6 \\
1.21 & & 5.7 & 13.9 & 1.9 & & & 6 \\
\hline Pamb (rev) & & 3 & & 3 & 2.9 & 1.8 & 2 \\
\hline
\end{tabular}

As shown in Figure 3 (where intruded species inside the CHA cage at selected P values are reported), up to $0.16 \mathrm{GPa}$, only water molecules enters the porosity (reaching a value of about 7 mol. per u.c., Table 3). At this stage, neither water-water nor water-framework bonding interactions are present. In figure TOT refined pattern obtained at $0.12 \mathrm{GPa}$ is reported. 


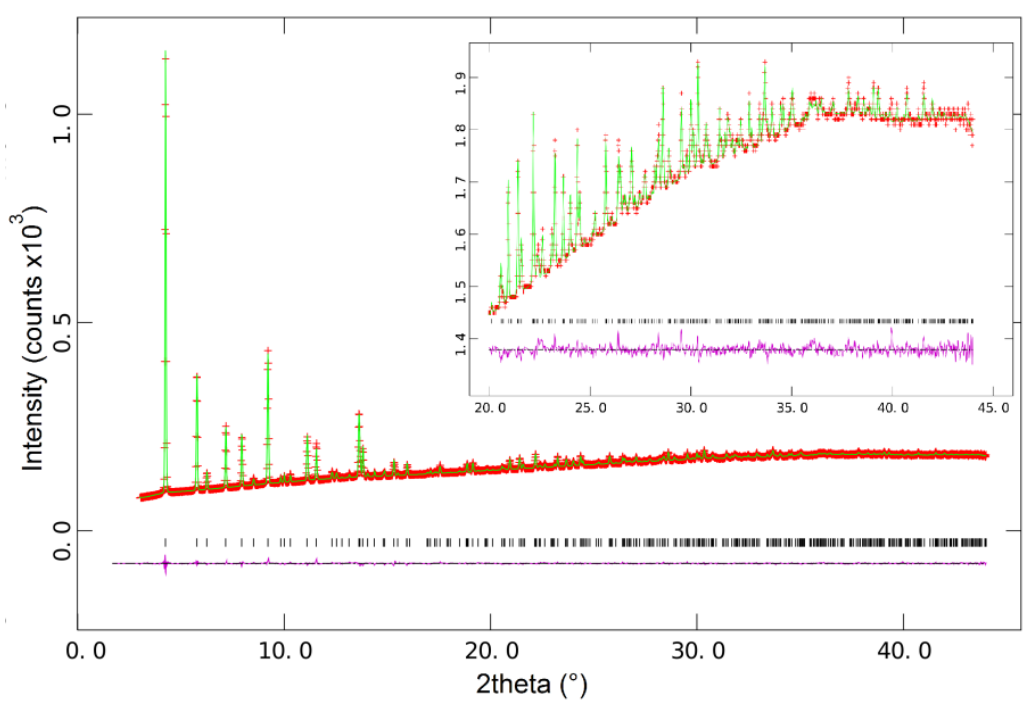

Figure TOT: Observed (red dash marks) and calculated (green line) diffraction patterns and final difference curve (purple line) from Rietveld refinements of Si-CHA under intrusion of $2 \mathrm{M} \mathrm{NaCl}$ aqueous solution at $0.12 \mathrm{GPa}$.

$\mathrm{Na}^{+}$and $\mathrm{Cl}^{-}$ions -at bonding distance $2.75 \AA$ - penetrate the zeolite cage at $0.26 \mathrm{GPa}$. Their amount rises reaching the maximum value of about $6 \mathrm{NaCl}$ molecules per u.c. at $0.36 \mathrm{GPa}$, accompanied by the increase of the water content. At $0.63 \mathrm{GPa}$, the structural arrangement of the extra-framework species inside CHA cage can be described as formed by two distinct "layers", not bonded to each other. The first layer is formed by a cluster of three water molecules (placed at about $3 \AA$ from the framework), while the second one contains two distinct $\mathrm{NaCl}$ molecules (Figure 3) with only weak interactions with the framework. Above $0.63 \mathrm{GPa}$, the available accessible volume decreases more slowly: water molecules continue to intrude, while the ions content remains almost constant.

At $1.21 \mathrm{GPa}$ the extra-framework species occupy the whole available accessible volume (Table 3 and Figure 2). Their structural organization - marked by the intensity change of some diffraction peaks - is radically changed (Figure 3): water is appreciably present also inside the double 6-ring (d6R), and an aggregate, formed by $\mathrm{H}_{2} \mathrm{O}$ and $\mathrm{NaCl}$, hydrogen-bonded to the framework occupies the $\mathrm{CHA}$ cage.

The structure refinement of the pattern collected upon decompression to $P_{a m b}\left(P_{a m b}(r e v)\right)$ reveals the irreversibility of the $\mathrm{NaCl}$ aqueous solution intrusion process: the original cell volume is not recovered (Figure 1) and some extra-framework species remain in the zeolite cavities (Figure 3). In each CHA cage, a chlorine anion coordinates one sodium cation and two water molecules (W2 and W5, at a distance of about 3 and $3.5 \AA$, respectively). The salt species are connected to the framework oxygen atoms by $\mathrm{Na}^{+}$cations and to silanol defects by $\mathrm{Cl}$ anion interactions $(\mathrm{Cl}-\mathrm{O} 1=3.4$ 
$\AA$, and $\mathrm{Cl}-\mathrm{O} 2=3.37 \AA$ ) . Additional water molecules, bonded to the framework, remain inside the d6R and in the CHA cage. Therefore, at $\mathrm{Pamb}_{\mathrm{am}}(\mathrm{rev})$, half of the cell accessible volume is still occupied by the intruded species.

\subsubsection{Structural features of the "Si-CHA/NaBr" system}

Figure 4 and Table 4 report the structural organization of the extra-framework species in the "Si$\mathrm{CHA} / \mathrm{NaBr} 2 \mathrm{M}^{\prime \prime}$ system at $0.96 \mathrm{GPa}$ and after decompression to ambient conditions. At $0.96 \mathrm{GPa}$, each CHA cage contains two molecular aggregates, interacting through water-water bonds. In each aggregate a bromine anion, bonded to a framework defect, is coordinated to Na, W7 and W3. W3 is, in turn, bonded to another water molecule (W1) placed in the middle of the so-called 8MR window. At this pressure, the accessible volume of the cage is completely occupied, except for the $\mathrm{d} 6 \mathrm{R}$, which is only partially filled by water.

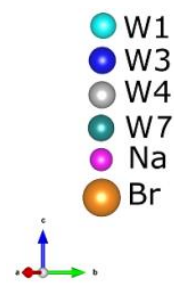

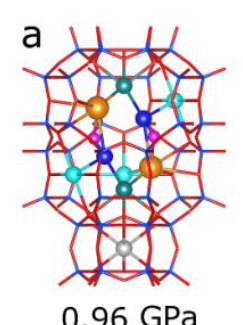

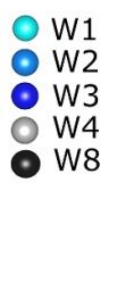

$0.96 \mathrm{GPa}$

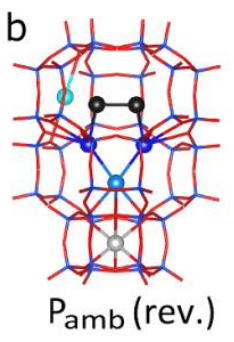

Figure 4: Results of the structure refinements at $0.96 \mathrm{GPa}$ (a) and after pressure release to ambient conditions $\left(\mathrm{Pamb}_{(\mathrm{rev}))}(\mathrm{b})\right.$ for Si-CHA intruded with $2 \mathrm{M} \mathrm{NaBr}$ solution.

Table 4: Number of salt/water molecules present in the unit cell of Si-CHA during the intrusion-extrusion process of $2 \mathrm{M}$ NaBr solution.

\begin{tabular}{lccccccc}
\hline Pressure (GPa) & W1 & W2 & W3 & W4 & W7 & W8 & NaBr \\
\hline 0.96 & 9 & & 6.5 & 0.5 & 7.5 & 5.5 \\
\hline Pamb (rev) & 1.6 & 3 & 4.5 & 3 & & 5.5 & \\
\hline
\end{tabular}

As already discussed for the "Si-CHA/NaCl" system (Table 2 and Figure 1), also for the "Si-CHA/NaBr" the intrusion phenomenon is not reversible, since the original cell volume is not recovered upon decompression. Concerning the extra-framework content, at $\mathrm{Pamb}_{\mathrm{am}}(\mathrm{rev})$ while $\mathrm{Na}^{+}$and $\mathrm{Br}^{-}$ions are released, some water molecules remain trapped inside the pores, occupying half of the available volume. A water cluster (made by one W2, two W3 and two W8 molecules, Figure 4b) is placed at 
the center of the cage, interacting with the framework. Far from the cluster, even W1 and W4 (in the $8 \mathrm{MR}$ window and in the $\mathrm{d} 6 \mathrm{R}$, respectively) remain trapped in the pores.

\subsubsection{Structural features of the "Si-CHA/CaCl 2 " system}

Figure 5 shows the variation of extra-framework content and of the residual available accessible volume (calculated as in 3.1.2. and taking into account $V_{C a}=4.19 \AA^{3}, V_{C l}=24.83 \AA^{3}, V_{W a t e r}=9.7 \AA^{3}$ ) during the intrusion of $\mathrm{CaCl}_{2}$ aqueous solution in $\mathrm{Si}-\mathrm{CHA}$. Up to $0.20 \mathrm{GPa}$ only water molecules were located in the zeolite pores. Their number in each unit cell increases from 2 to 10 between 0.10 and $0.20 \mathrm{GP}$ (Table 5). Above this pressure the water amount increase is accompanied by the initial intrusion of $\mathrm{Ca}^{2+}$ and $\mathrm{Cl}^{-}$ions (Figure 6). At $0.62 \mathrm{GPa}$, Ca site is at coordination distance with two $\mathrm{Cl}^{-}$ sites. Each anion is linked to a framework silanol and bonded to the water molecule $\mathrm{W} 1_{\mathrm{B}}$, located in the neighboring cage (Figure $6 \mathrm{~d}$ ). As a whole, each cage hosts six water molecules: four $\mathrm{W} 1_{B}$, one W2 and one W3 (Figure 6c). This arrangement is very stable also at higher pressure (0.82 GPa, Figure 6d). During decompression (Figure 6e and Table 5), almost all the extra-framework content is released and at ambient conditions chabazite recovers its original cell volume (Figure 1).

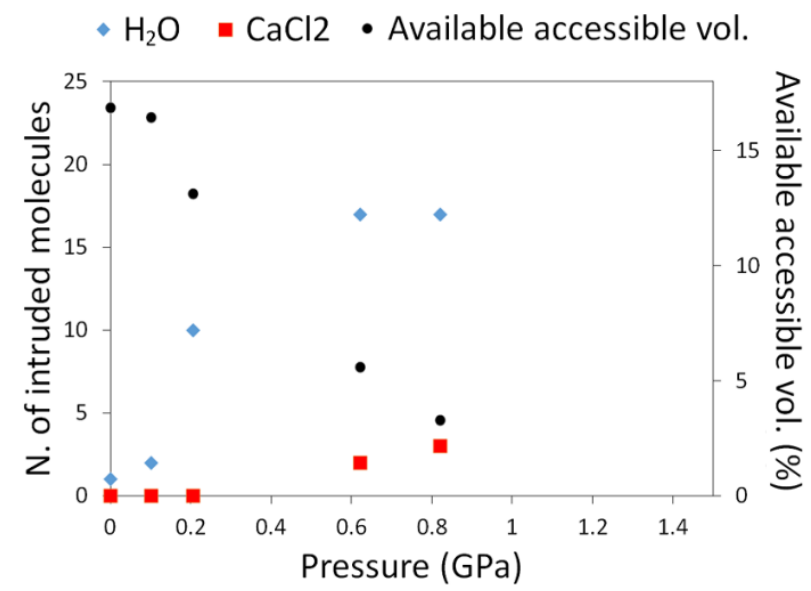

Figure 5: Extra-framework cell content, in terms of molecules number, and the available accessible volume (values related to the secondary axis) are reported as a function of the pressure during the intrusion process in the "Si$\mathrm{CHA} / \mathrm{CaCl}_{2} 2 \mathrm{M}$ “system. 


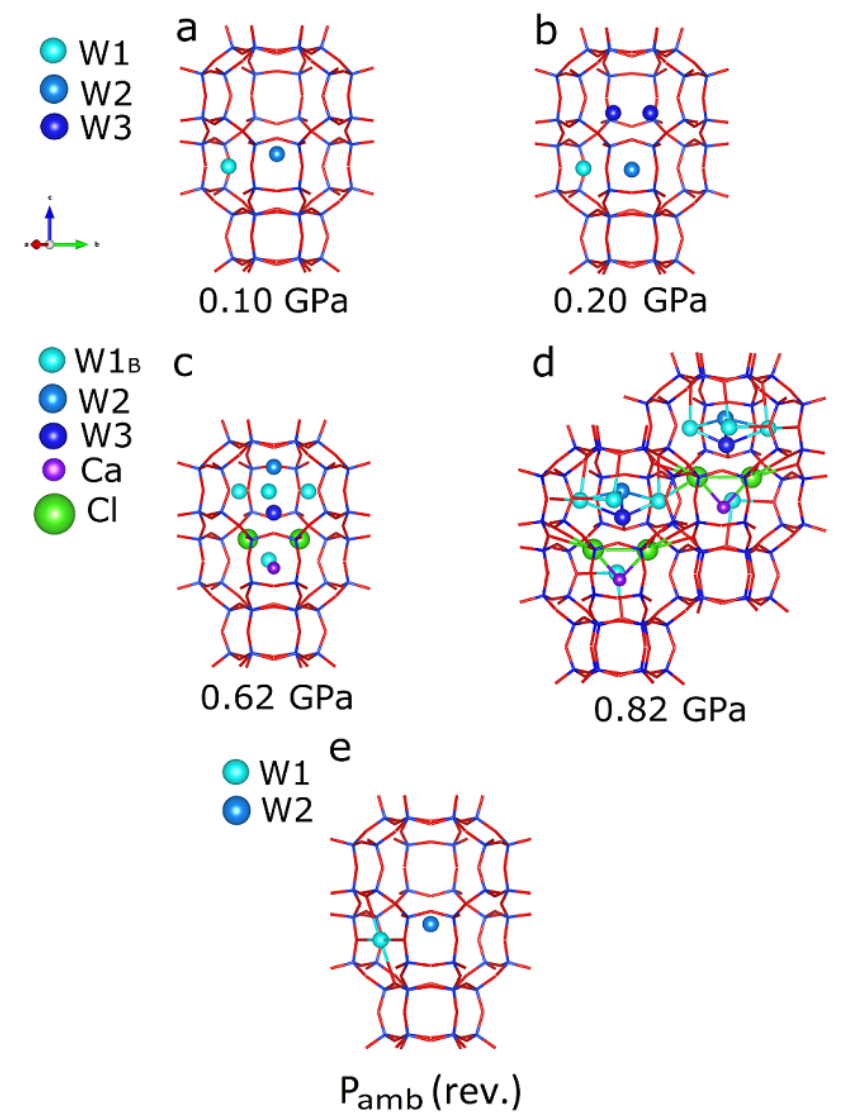

Figure 6: Structural evolution of the extra-framework atoms as a function of the pressure during the intrusion-extrusion process of $2 \mathrm{M} \mathrm{CaCl}_{2}$ aqueous solution in Si-chabazite. For sake of clarity, bond distances are drawn only for the structure at highest pressure and after pressure release. In figure d) interaction between two neighboring cages is displayed.

Table 5: Salt/water molecules cell content as function of the pressure during the intrusion-extrusion process in the "Si$\mathrm{CHA} / \mathrm{CaCl}_{2} 2 \mathrm{M}^{\prime \prime}$ system.

\begin{tabular}{llllll}
\hline Pressure (GPa) & W1 & W1 & W2 & W3 & $\mathrm{CaCl}_{2}$ \\
\hline 0.10 & 0.4 & & 1.6 & & \\
0.20 & 2.4 & 11.2 & 1.1 & 6.6 & \\
0.62 & & $3 \mathrm{fix}$ & $3.4 \mathrm{fix}$ & 2.5 \\
0.82 & & $3 \mathrm{fix}$ & $3.3 \mathrm{fix}$ & 3 \\
\hline Pamb (rev) & 0.5 & 2 & & \\
\hline
\end{tabular}

\subsection{Results of porosimetric measurements}

Figure 7 shows the P-V diagrams determined for three intrusion-extrusion porosimetric cycles on Si$\mathrm{CHA} / \mathrm{NaBr}$, Si-CHA/NaCl and $\mathrm{Si}-\mathrm{CHA} / \mathrm{CaCl}_{2}$ systems, using both $2 \mathrm{M}$ and $3 \mathrm{M}$ concentrations of the electrolyte solutions. The curves are shifted along the Y-axis for a better visibility. The 0-2 MPa range 
on X-axis is not shown (for $2^{\text {nd }}$ and $3^{d}$ cycles), since the observed volume variation in this pressure range corresponds to the intrusion of liquid in the interparticular porosity of the pellet (see $1^{\text {st }} \mathrm{cycle}$ ). Only the first two cycles are presented, since the $2^{\text {nd }}$ and the $3^{\text {d }}$ ones are superimposable. The measurements were performed up to the pressure of $350 \mathrm{MPa}$, but only the $0-150 \mathrm{MPa}$ range is shown for better visibility, because no volume variation is observed after $130 \mathrm{MPa}$. The intrusionextrusion characteristics are reported in Table 6.

In the first cycle, a partially irreversible intrusion is observed for all the systems that exhibit a combination of bumper (partially irreversible intrusion) and shock-absorber (reversible intrusion with relatively large hysteresis) behavior. In the following cycles, the intrusion is fully reversible and the systems display a spring behavior with a small hysteresis between the intrusion and the extrusion curves. The same behavior was previously observed for the "Si-CHA/water" system ${ }^{30}$. As expected, the use of electrolyte solutions allows to increase significantly the intrusion pressure, which, in turn, increases with the salt concentration (from $29 \mathrm{MPa}$ for pure water ${ }^{30}$ up to $90 \mathrm{MPa}$ for $3 \mathrm{M} \mathrm{CaCl}_{2}$ aqueous solution). The decrease of the intrusion pressure from the $1^{\text {st }}$ to $2^{\text {nd }}$ cycle can be ascribed to the formation of hydrophilic silanol defects into the zeosil pores after the first cycle.

Figure 7. Intrusion-extrusion curves of the " $\mathrm{Si}-\mathrm{CHA} / \mathrm{NaBr} 2 \mathrm{M}$ », " $\mathrm{Si}-\mathrm{CHA} / \mathrm{NaCl} 2 \mathrm{M}$ », " $\mathrm{Si}-\mathrm{CHA} / \mathrm{NaCl} 3 \mathrm{M}$ ", " $\mathrm{Si}-\mathrm{CHA} / \mathrm{CaCl}_{2} 2 \mathrm{M}$ » and " $\mathrm{Si}-\mathrm{CHA} / \mathrm{CaCl}_{2} 3 \mathrm{M}$ » systems. The curves are shifted along $\mathrm{Y}$ axis for a better visibility.

Table 6. The characteristics of "CHA-type zeosil / $\mathrm{NaBr}, \mathrm{NaCl}$ or $\mathrm{CaCl}_{2}$ solution" systems: Intrusion ( $\left.\mathrm{P}_{\text {int }}\right)$ and Extrusion $\left(P_{\text {ext }}\right)$ Pressures, Intruded $\left(V_{\text {int }}\right)$ and Extruded $\left(V_{\text {ext }}\right)$ Volumes, System behavior.

\begin{tabular}{cccccc}
\hline System & $\mathrm{P}_{\text {int }}(\mathrm{MPa})$ & $\mathrm{P}_{\text {ext }}(\mathrm{MPa})$ & $\mathrm{V}_{\text {int }}(\mathrm{mL} / \mathrm{g})$ & $\mathrm{V}_{\text {ext }}(\mathrm{mL} / \mathrm{g})$ & Behavior \\
\hline Si-CHA/NaBr 2 M & $44 * / 39^{* *}$ & 35 & $0.165^{*} / 0.135^{* *}$ & 0.135 & $\mathrm{~B}+\mathrm{SA} * / \mathrm{S}^{* *}$ \\
$\mathrm{Si}-\mathrm{CHA} / \mathrm{NaCl} 3 \mathrm{M}$ & $54 * / 47^{* *}$ & 41 & $0.170^{*} / 0.135^{* *}$ & 0.135 & $\mathrm{~B}+\mathrm{SA} * / \mathrm{S}^{* *}$ \\
$\mathrm{Si}-\mathrm{CHA} / \mathrm{NaCl} 2 \mathrm{M}$ & $44 * / 38^{* *}$ & 35 & $0.170^{*} / 0.135^{* *}$ & 0.135 & $\mathrm{~B}+\mathrm{SA} * / \mathrm{S}^{* *}$ \\
$\mathrm{Si}-\mathrm{CHA} / \mathrm{CaCl}_{2} 2 \mathrm{M}$ & $60 * / 55^{* *}$ & 47 & $0.130^{*} / 0.115^{* *}$ & 0.115 & $\mathrm{~B}+\mathrm{SA} * / \mathrm{S}^{* *}$ \\
$\mathrm{Si}-\mathrm{CHA} / \mathrm{CaCl}_{2} 3 \mathrm{M}$ & $90 * / 83^{* *}$ & 72 & $0.130^{*} / 0.105^{* *}$ & 0.105 & $\mathrm{~B}+\mathrm{SA} * / \mathrm{S}^{* *}$ \\
\hline
\end{tabular}

$*-1^{\text {st }}$ cycle; $* *-2^{\text {nd }}$ and $3^{\mathrm{d}}$ cycles. $\mathrm{B}=$ Bumper, $\mathrm{SA}=$ Shock Absorber, $\mathrm{S}=$ Spring.

\subsection{Other characterization}


The Si-CHA sample was characterized before and after intrusion-extrusion experiments of $\mathrm{NaBr}$ aqueous solution $2 \mathrm{M}$ by thermogravimetric analysis, nitrogen adsorption-desorption and ${ }^{29} \mathrm{Si}$ solidstate NMR spectroscopy. The detailed description of the characterization is presented in Supporting Information. ${ }^{29} \mathrm{Si}$ solid-state NMR spectroscopy provides some important information concerning the interpretation of the results of X-ray diffraction. The ${ }^{29} \mathrm{Si}$ MAS NMR and ${ }^{1} \mathrm{H}-{ }^{29} \mathrm{Si} \mathrm{CPMAS} \mathrm{NMR}$ (insert) spectra of the Si-CHA samples before and after intrusion-extrusion experiments in $2 \mathrm{M} \mathrm{NaBr}$ aqueous solution are shown in Figure S3. The spectra of the starting material exhibits a well-defined resonance at $-111.5 \mathrm{ppm}$ attributed to $\mathrm{Q}_{4}$ groups ( $\left.\mathrm{Si}(\mathrm{OSi})_{4}\right)$ which can be assigned to the unique crystallographic site of chabazite framework. A small broad component accounting for $7.0 \%$ of the total ${ }^{29} \mathrm{Si}$ signal is also detected at around $-102 \mathrm{ppm}$. The latter can be assigned to $\mathrm{Q}_{3}$ groups (HO-Si$(\mathrm{OSi})_{3}$ or $\left.-\mathrm{O}-\mathrm{Si}-(\mathrm{OSi})_{3}\right)$. From the CPMAS spectra, the component a $-102 \mathrm{ppm}$ is considerably enhanced revealing that the $\mathrm{Q}_{3}$ groups correspond to silanol groups. The spectra of the intruded sample is close to the one of nonintruded material and exhibits the same resonances, but the component of $\mathrm{Q}_{3}$ groups increases to $9.3 \%$ of the total ${ }^{29} \mathrm{Si}$ signal.

The CPMAS spectra confirm such evolution of the signal of $\mathrm{Q}_{3}$ groups. After intrusionextrusion experiments their number increases since the relative intensity ratio between the $\mathrm{Q}_{3}$ and $\mathrm{Q}_{4}$ components for the two samples is inversed.

The presence of silanol groups and their formation under intrusion-extrusion experiments allow to explain some particularities of porosimetry results such as a partially irreversible intrusion in the first cycle and slight lowering of intrusion pression in $2^{\text {nd }}$ and $3^{d}$ ones. They play also a role in the coordinating of intruded species.

\section{Discussion}

\subsection{Cell parameters behavior}

The pressure dependences of the cell parameters of the three Si-CHA/electrolyte systems display some interesting similarities. To interpret them, the unit cell evolutions can be related to the variations of the intruded extra-framework volume (or, in other words, to the residual available accessible volume). Regardless the composition of the systems, three main sections are evident in Figure 8: 


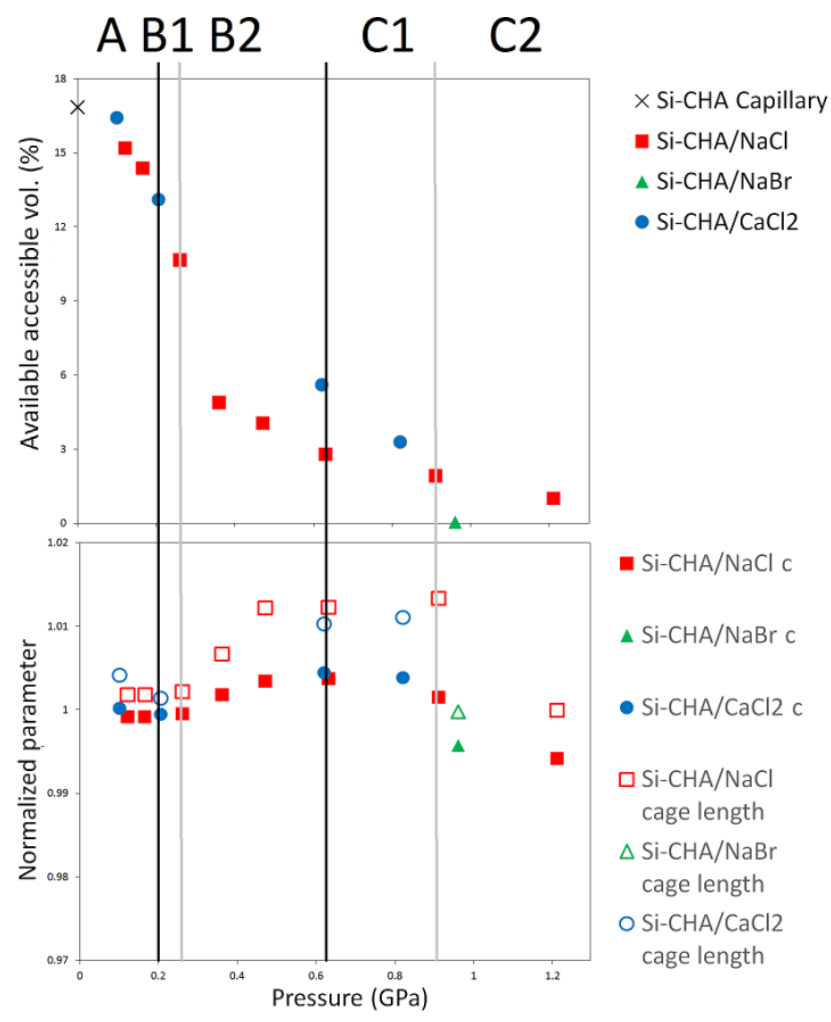

Figure 8: Available accessible cell volume of the investigated systems (top) and evolution of $c$ parameter and of the $\mathrm{CHA}$ cage length (bottom) as a function of pressure. Three main sections are evidenced and correlated with the structural evolution, as explained in the body text.

i) A section (0.12-0.20 GPa): cell volume compression is related to a slight $c$ reduction. $\mathrm{CHA}$ cage is almost empty, except for some water molecules (two of them already present in the Si-CHA at $\mathrm{Pamb}_{\mathrm{am}}$.

ii) B section (0.20-0.63 GPa): at 0.26 GPa (B1 section), ions start to enter the zeolite in the Si$\mathrm{CHA} / \mathrm{NaCl}$ system, (see Figure 2). The penetration of $\mathrm{CaCl}_{2}$ molecule is observed from $0.62 \mathrm{GPa}$, even if we can not excluded a penetration in early stages of compression due to the lack of diffraction data in the range $0.20-0.62 \mathrm{GPa}$. It is reasonable to suppose that a certain pressure is required to induce ion desolvatation in the aqueous solution, so allowing their intrusion into chabazite pores ${ }^{37}$. Ion content increases as a function of pressure and at $0.63 \mathrm{GPa} \mathrm{NaCl}$ and $\mathrm{CaCl}_{2}$ molecules reach the number of 6 and 2.5 per unit cell, respectively, while the water molecules are 17 in both cases (section $\mathrm{B} 2$ ). In this $\mathrm{P}$ range, $a$ axis slightly decreases, whereas $c$ undergoes a significant increment. This variation is mainly driven by the deformation of CHA cage, which stretches in order to accommodate the increasing extra-framework intruded species (Figure 8).

iii) C section ( $P>0.63 \mathrm{GPa}$ ): between 0.63 and $0.90 \mathrm{GPa}$ ( $\mathrm{C} 1$ section), water content increases, while ions content remains almost stable. The available accessible volume is less than $3 \%$ and decreases even more as an effect of further water penetration. This trend is more evident above 
$0.90 \mathrm{GPa}$. In $\mathrm{C} 2$ section, $\mathrm{CHA}$ cage is completely filled in both the studied systems ( $\mathrm{NaCl}$ and $\mathrm{NaBr}$ ) and just few water molecules can be intruded in the d6R. At this stage, the electrolyte solutions in the diamond anvil cell (DAC) behave essentially as non-penetrating P-transmitting media inducing a relevant decrease of the $c$ axis and of the unit cell volume (Figure 8).

\subsection{Structural modifications induced by intrusion/extrusion processes}

The intrusion of Si-CHA by different electrolyte aqueous solutions induces noticeable structural modifications in all the investigated systems. Referring again to Figure 8 and to the results of the structure refinements, it can be observed that:

i) Regardless the penetrating media, in A section water molecule configuration changes coherently with pressure: W1 and W2, already existing in Si-CHA at ambient conditions, increase their contents and at $0.12 \mathrm{GPa}$ a new position, labeled $\mathrm{W} 3$, is occupied. No significant framework deformation is observed in this P range, neither in CHA cage nor in the $\mathrm{d} 6 \mathrm{R}$.

ii) After ion intrusion, noticeable differences in the nature, amount (Figures 2 and 5) and arrangement (Figures 3, 4 and 6) of the extra-framework contents are visible, depending on the intruded electrolyte solution. This is especially evident observing the structures of the three systems at the highest investigated pressures. Let us compare first Si-CHA/NaCl at $1.21 \mathrm{GPa}$ and $\mathrm{Si}-\mathrm{CHA} / \mathrm{NaBr}$ at $0.96 \mathrm{GPa}$. In both cases, two symmetry-related aggregates (made by one salt and three water molecules), interacting each other, occupy $\mathrm{CHA}$ cage. It is worth noticing that the framework/extraframework interactions in these systems are driven by the silanol defects. In fact, the two anions $\left(\mathrm{Cl}^{-}\right.$and $\left.\mathrm{Br}^{-}\right)$are placed at bonding distance to the framework silanols (3.13-3.27 $\AA$ and $3.24 \AA$, respectively). Chlorine site is near the $8 \mathrm{MR}$-window, whereas bromine near the $4 \mathrm{MR}$ window. $\mathrm{Br}^{-}$is more weakly bonded to the framework than $\mathrm{Cl}^{-}$(Table 7), consistent with the lower charge density of bromine. In both systems, cations are in a inner position with respect to the anions in the cage and coordinates one water molecule. The main differences between the arrangements of the two extra-framework aggregates concern the water bonding systems. In "Si-CHA/NaCl" three water molecules are linked to each chlorine ion (bond lengths $\sim 3.0$ and $\sim 3.3 \AA$ ), making this cluster rather compact and solidly bonded to the framework through six anion-silanol and one water-framework interactions. Differently, in $\mathrm{Si}-\mathrm{CHA} / \mathrm{NaBr}$, bromine is bonded to the framework by three anion-silanol interactions and it is connected to a cluster of three water molecules (W1, W3 and W7), in turn bonded to the framework. 
In $\mathrm{Si}-\mathrm{CHA} / \mathrm{CaCl}_{2}$ at $0.82 \mathrm{GPa}$, the extra-framework content is organized in a further different configuration (Figure 6): each cage hosts a $\mathrm{CaCl}_{2}$ molecule and a water cluster. The bonding of the two species possibly occurs only through adjacent cages. Also in this system, the interaction between the framework and the salt molecules occurs through the two anions, by one short and two long distances (Table 7).

Table 7: Anion-framework bond distances of the three systems at the highest investigated pressure.

\begin{tabular}{llllll}
\hline \multicolumn{2}{c}{$\mathrm{Si}-\mathrm{CHA} / \mathrm{NaCl} 1.210 \mathrm{GPa}$} & \multicolumn{2}{c}{$\mathrm{Si}-\mathrm{CHA} / \mathrm{NaBr} 0.960 \mathrm{GPa}$} & \multicolumn{2}{c}{$\mathrm{Si}-\mathrm{CHA} / \mathrm{CaCl}_{2} 0.820 \mathrm{GPa}$} \\
\hline $\mathrm{O} 1-\mathrm{Cl}$ & $3.136(9)$ & $\mathrm{O} 1-\mathrm{Br}$ & $3.456(7)$ & $\mathrm{O} 1-\mathrm{Cl}$ & $3.265(6)$ \\
$\mathrm{O} 1-\mathrm{Cl}$ & $3.248(9)$ & $\mathrm{O} 4-\mathrm{Br}$ & $3.242(4)$ & $\mathrm{O}-\mathrm{Cl}$ & $3.322(7)$ \\
$\mathrm{O} 2-\mathrm{Cl}$ & $3.371(6)$ & $\mathrm{O} 4-\mathrm{Br}$ & $3.242(4)$ & $\mathrm{O} 2-\mathrm{Cl}$ & $3.322(7)$ \\
$\mathrm{O} 2-\mathrm{Cl}$ & $3.371(6)$ & & & & \\
$\mathrm{O} 4-\mathrm{Cl}$ & $3.277(6)$ & & & & \\
$\mathrm{O} 4-\mathrm{Cl}$ & $3.277(6)$ & & & & \\
\hline
\end{tabular}

iii) Despite the structural differences above described, some general features emerge from the intrusion/extrusion processes of the three investigated systems. As previously discussed, regardless the nature of the electrolyte aqueous solution, the framework/extra-framework interactions are mainly driven by the bonding of the anions to the silanol defects present in CHA framework. On the contrary, both sodium and calcium coordinate the respective anion without any additional interactions with the framework. In addition, water molecules can be intruded in the $\mathrm{d} 6 \mathrm{R}$ only above a relatively high pressure ( $\sim 0.9 \mathrm{GPa})$, after the almost complete filling of $\mathrm{CHA}$ cage.

iv) As previously discussed, all the systems show different behaviors upon pressure release. While the intrusion process of $\mathrm{CaCl}_{2}$ is reversible $\mathrm{Si}-\mathrm{CHA} / \mathrm{NaCl}$ and $\mathrm{Si}-\mathrm{CHA} / \mathrm{NaBr}$ do not recover their initial cell volume. Specifically, in $\mathrm{Si}-\mathrm{CHA} / \mathrm{NaCl}$ system, both $\mathrm{NaCl}$ and water molecules partially remain trapped inside zeolite pores; in Si-CHA/NaBr system, only $\mathrm{NaBr}$ is released while water molecules remain inside chabazite pores. The response to decompression of the three systems can be interpreted on the basis of the strength of the bonds among the framework and the extraframework species: the most strongly bonded species remain trapped inside the pores during decompression.

\subsection{Porosimetry data and comparison with the XRPD data}

The results of HP XRPD have been compared with ones of porosimetric experiments. However, it should be taken into account that the pressure values measured during the two experiments cannot be directly compared that is possibly related to the different kinetics conditions under which 
pressure is applied. Specifically, in the experiments with diamond anvil cell, the applied pressure (in the GPa range) increases rapidly, whereas an intrusion-extrusion cycle with the porosimeter takes 1.5 hour (pressures in the MPa range). It could be supposed that in the case of diamond anvil cell, this extremely rapid pressure rise does not allow the intrusion of the liquid in such fast time, thus, to overpass this kinetics limitation a higher pressure should be applied to penetrate solution species inside the pores.

P-V curves, obtained by porosimetric experiments and shown in section 3.2 (Figure 7), look very similar for the "Si-CHA/NaBr $2 \mathrm{M}$ " and " $\mathrm{Si}-\mathrm{CHA} / \mathrm{NaCl} 2 \mathrm{M}$ " systems, suggesting no influence of anion nature on the intrusion process. It is known that in the case of highly concentrated solutions the influence of the anion nature can be very strong ${ }^{54}$, but in relatively diluted ones the intrusion process seems to be more ruled by water molecules.

Concerning the cation, the influence of its nature on the intrusion pressure is significant: a higher pressure is measured in the case of $\mathrm{CaCl}_{2}$ solutions with respect to $\mathrm{NaCl}$ one (see table 6). This can be related to the stronger interactions that $\mathrm{Ca}^{2+}$ ion establishes with the water molecules of its solvation shell.

Another peculiarity of the porosimetric results obtained using $\mathrm{CaCl}_{2}$ with respect to $\mathrm{NaCl}$ and $\mathrm{NaBr}$ solutions, is the lower intruded volume accompanied by a higher reversibility in the first intrusion cycle. This last finding is in complete agreement with the in situ HP synchrotron XRPD results (see above). More in detail, the intruded volume for sodium salt solutions is $\sim 0.165-0.170 \mathrm{~mL} / \mathrm{g}$ in the first cycle, the extruded one is of $\sim 0.135 \mathrm{~mL} / \mathrm{g}$, corresponding to an irreversibly intruded volume of 0.030-0.035 mL/g; for $\mathrm{CaCl}_{2}$ solutions the intruded volume is $0.130 \mathrm{~mL} / \mathrm{g}$ with an irreversibly intruded one of $0.015-0.025 \mathrm{~mL} / \mathrm{g}$.

Despite the differences in the measured pressure values between the two types of experiments (porosimeter vs. diamond anvil cell), whatever the system, the intruded volumes determined by porosimetric measurements are in quite good agreement with the amount of extra-framework species determined by in situ HP synchrotron XRPD. The comparison of experimental and calculated values of the intruded volume given in Table 8 clearly indicates a close match between the corresponding values. The calculated intruded volumes have been derived from the number of extra-framework species supposing that these are the water molecules which determine mainly the solution volume. 
Other correlations could be found between the results of the two types of experiments. At HP, the XRPD data show that the system Si-CHA/CaCl 2 contains $3 \mathrm{CaCl}_{2}$ and $17.5 \mathrm{H}_{2} \mathrm{O}$ molecules per unit cell, whereas $6 \mathrm{NaCl} \cdot 21.5 \mathrm{H}_{2} \mathrm{O}$ or $5.5 \mathrm{NaBr} \cdot 23.3 \mathrm{H}_{2} \mathrm{O}$ are present in $\mathrm{Si}-\mathrm{CHA} / \mathrm{NaCl}$ and $\mathrm{Si}-\mathrm{CHA} / \mathrm{NaBr}$, respectively. The lower amount of intruded species present in $\mathrm{Si}-\mathrm{CHA} / \mathrm{CaCl}_{2}$ is in agreement with the lower value of the intruded volume measured by porosimetry $(0.130 \mathrm{~mL} / \mathrm{g}$ against $0.165-0.170 \mathrm{~mL} / \mathrm{g}$ for calcium and sodium salt solutions, respectively).

Table 8. Experimental and calculated values of intruded volume for $\mathrm{NaBr}, \mathrm{NaCl}$ and $\mathrm{CaCl}_{2}$ solutions.

\begin{tabular}{|c|c|c|c|}
\hline System & $\begin{array}{c}\mathrm{H}_{2} \mathrm{O} \\
\text { molecules per } \\
\text { unit cell }^{\mathrm{a}}\end{array}$ & $\begin{array}{l}\text { Calculated intruded volume } \\
\qquad(\mathrm{mL} / \mathrm{g})\end{array}$ & $\begin{array}{l}\text { Intruded volume in } 1^{\text {st }} \text { cycle }^{\mathrm{c}} \\
(\mathrm{mL} / \mathrm{g})\end{array}$ \\
\hline Si-CHA/NaBr 2 M & 23.3 & 0.19 & 0.165 \\
\hline Si-CHA/NaCl 2 M & 21.5 & 0.18 & 0.170 \\
\hline $\mathrm{Si}-\mathrm{CHA} / \mathrm{CaCl}_{2} 2 \mathrm{M}$ & 17.5 & 0.145 & 0.130 \\
\hline
\end{tabular}

\subsection{Discussion on composition of intruded species}

This work has provided original structural results on both composition and site position of the extraframework species penetrated in Si-CHA during intrusion/extrusion experiments with $\mathrm{NaCl}, \mathrm{NaBr}$ and $\mathrm{CaCl}_{2}$ aqueous solutions. Now, it is interesting to comparatively discuss the behavior of the different electrolyte solutions, related to the results of the only other intrusion/extrusion XRPD study reported in literature, concerning the penetration of $\mathrm{MgCl}_{2}$ aqueous solution in a Si-ferrierite 37.

The initial composition of the electrolyte solutions used in the present study is approximately $1 \mathrm{CaCl}_{2}$ ( $\mathrm{NaCl}$, or $\mathrm{NaBr}) \cdot 17$ or $26 \mathrm{H}_{2} \mathrm{O}$ for 2 and $3 \mathrm{M}$ solutions, respectively. At HP, the unit cell of the system $\mathrm{Si}-\mathrm{CHA} / \mathrm{CaCl}_{2}$ contains $3 \mathrm{CaCl}_{2}$ species and 17.5 water molecules (see Fig. 5 and Table 5). This content corresponds to the composition $\mathrm{CaCl}_{2} \cdot 5.8 \mathrm{H}_{2} \mathrm{O}$, close to that of a saturated $\mathrm{CaCl}_{2}$ aqueous solution $\left(\mathrm{CaCl}_{2} \cdot 6.6 \mathrm{H}_{2} \mathrm{O}\right)$. A similar result was obtained in our previous work on the intrusion of $\mathrm{MgCl}_{2}$ solution in Si-FER, where the concentration of the intruded liquid was considerably higher than that 
of the initial solution $\left(\mathrm{MgCl}_{2} \cdot 21 \mathrm{H}_{2} \mathrm{O}\right)$ and close to that of a saturated $\mathrm{MgCl}_{2}$ aqueous solution $\left(\mathrm{MgCl}_{2} \cdot 10 \mathrm{H}_{2} \mathrm{O}\right)^{37}$.

Particularly remarkable results on the compostion of intruded species have been obtained. From the experiments performed with $2 \mathrm{M} \mathrm{NaBr}$ solution, the resulting intruded fraction under $\mathrm{HP}$ has the composition $\mathrm{NaBr} \cdot 4.2 \mathrm{H}_{2} \mathrm{O}$ (simplified from $5.5 \mathrm{NaBr} \cdot 23.33 \mathrm{H}_{2} \mathrm{O}$ ), that is more concentrated than the corresponding $\mathrm{NaBr}$ saturated aqueous solution $\left(\mathrm{NaBr} \cdot 6 \mathrm{H}_{2} \mathrm{O}\right)$.

In the case of $\mathrm{NaCl}$, the effect of the intrusion on the concentration of the intruded fraction is even more pronounced: in the P range 0.26-1.21 GPa the composition of the intruded solution varies from $\mathrm{NaCl} \cdot 2.5 \mathrm{H}_{2} \mathrm{O}$ to $\mathrm{NaCl} \cdot 3.6 \mathrm{H}_{2} \mathrm{O}$ (to be compared to $\mathrm{NaCl} \cdot 9 \mathrm{H}_{2} \mathrm{O}$ for the saturated one). Hence, the concentration of the intruded solution is not only much higher than the initial one, but it can even largely overpass the concentration of the corresponding saturated solution. This can be interpreted with the high affinity and the stable bonds of the guest ions with the zeosil framework. These results reinforce the hypothesis that the increase of the intrusion pressure when electrolyte solutions are used instead of pure water is determined by the desolvation of the ions. They can also open new perspectives in research fields such as water desalination, ions separation etc.

It should be also noticed that the composition of the intruded phase varies with the applied pressure. At low pressure the water is preferentially intruded into chabazite porosity, whereas at higher pressure also the ions penetrate into the pores and the intruded "solution" becomes more concentrated.

\section{Conclusions}

In the present work a pure silica chabazite has been intruded at HP by 3 different electrolyte aqueous solutions with different concentrations $\left(\mathrm{NaCl}, \mathrm{NaBr}\right.$ and $\mathrm{CaCl}_{2}$ with $2 \mathrm{M}$ and $3 \mathrm{M}$ initial concentration). Regardless the nature of the penetrating medium, the results of this study show that:

- The use of electrolyte solutions instead of pure water allows increasing significantly the intrusion pressure, which increases with the salt concentration. The nature of the cation in the salt seems to influence the intrusion-extrusion pressures with higher values obtained for the salts with $\mathrm{Ca}^{2+}$ as cation compared to the one with $\mathrm{Na}^{+}$cation. 
- The composition of intruded species is different from that of initial solution and depends on applied pressure. Both water and salts penetrate chabazite pores under HP, with salt entering at a second stage with respect water. The resulting intruded fractions is considerably more concentrated than initial electrolyte solutions and even more than saturated solutions of corresponding salts.

- The different composition between intruded fraction and initial solution reinforces the hypothesis on ion desolvation under penetration into the pores as a main reason of intrusion pressure increase.

- The initial concentration ( $2 \mathrm{M}$ or $3 \mathrm{M})$ of the electrolyte solution has no significant influence on the chabazite structural evolution and on the host-guest interactions of the intruded species.

- From porosimetry experiment, in the first cycle, a partially irreversible intrusion is observed for all the systems that exhibit a combination of bumper and shock-absorber behavior. In the following cycles, the intrusion is fully reversible and the systems display a spring behavior with a small hysteresis between the intrusion and the extrusion curves.

Despite these similarities, the three systems show important differences upon pressure release, in terms of nature and amount of the retained intruded volume. These differences are linked to the presence of silanol defects, which play a crucial role in promoting the interactions with the intruded anions and in influencing the reversibility of the process.

\section{Supporting Information Description}

In the Supporting Information experimental description of thermogravimetric analysis, nitrogen adsorption-desorption and ${ }^{29} \mathrm{Si}$ solid-state NMR spectroscopy is shown. In addition, selected structures are reported in details.

\section{Acknowledgment}

Authors thank the staff of SNBL1 (BM01) beamline at ESRF (Grenoble, France), BL04-MSPD beamline at Alba (Barcelona, Spain) and XPRESS beamline at ELETTRA (Trieste, Itay) for their help during XRPD data collections. Giorgia Confalonieri and Rossella Arletti were supported by Ricerca 
locale ex 60\% 2016-2017 - "Intrusione forzata di soluzioni elettrolitiche in matrici porose: migliorare le prestazioni energetiche di zeoliti".

\section{References}

1. Eroshenko, V. A., Heterogeneous Structure for Accumulation or Dissipation of Energy, Process to Use It and Associated Devices. Int. Patent WO96/18040 1996.

2. Eroshenko, V. A., URSS Patent 13338701985.

3. Eroshenko, V. A., Popyk, A., Current Status and Perspectives of Thermomolecular Engine Developments. Int. J. Thermodyn. 2014, 17 (1), 33-41.

4. Coiffard, L.; Eroshenko, V. A.; Grolier, J. P. E., Thermomechanics of the Variation of Interfaces in Heterogeneous Lyophobic Systems. AichE J. 2005, 51 (4), 1246-1257.

5. Laouir, A.; Luo, L.; Tondeur, D.; Cachot, T.; Le Goff, P., Thermal Machines Based on Surface Energy of Wetting: Thermodynamic Analysis. AichE J. 2003, 49 (3), 764-781.

6. Eroshenko, V. A.; Piatiletov, I.; Coiffard, L.; Stoudenets, V., A New Paradigm of Mechanical Energy Dissipation: Experimental Investigation and Effectiveness of a Novel Car Damper. J. Proc. Mech Eng., Part D: J. Automob. Eng. 2007, 221 (D3), 301-312.

7. Eroshenko, V. A., A new paradigm of mechanical energy dissipation: Theoretical Aspects and Practical Solutions. J. Proc. Mech Eng., Part D: J. Automob. Eng. 2007, 221 (D3), 285-300.

8. Suciu, C. V.; Iwatsubo, T.; Yaguchi, K.; Ikenaga, M., Novel and Global Approach of the Complex and Interconnected Phenomena Related to the Contact Line Movement Past a Solid Surface from Hydrophobized Silica Gel. J. Coll. Inter. Sci. 2005, 283 (1), 196-214.

9. Suciu, C. V.; Yaguchi, K., Endurance Tests on a Colloidal Damper Destined to Vehicle Suspension. Exp. Mec. 2009, 49 (3), 383-393.

10. Eroshenko, V. A., Interfacial Energy in the Lyophobic Systems and Challenge to All Physico-Chemists. In The Eights International Conference on Material Technologies and Modeling, MMT-2014, Ariel, Israel 2014.

11. Eroshenko, V. A.; Fadeev, A. Y., Intrusion and Extrusion of Water in Hydrophobized Porous Silica. Colloid J. 1995, 57 (4), 446-449.

12. Fadeev, A. Y.; Eroshenko, V. A., Study of Penetration of Water into Hydrophobized Porous Silicas. J. Coll. Inter. Sci. 1997, 187 (2), 275-282.

13. Eroshenko, V.; Regis, R. C.; Soulard, M.; Patarin, J., Energetics: A New Field of Applications for Hydrophobic Zeolites. J. Am. Chem. Soc. 2001, 123 (33), 8129-8130.

14. Ronchi, L.; Nouali, H.; Daou, T. J.; Patarin, J.; Ryzhikov, A., Heterogeneous Lyophobic Systems Based on Pure Silica ITH-type Zeolites: High Pressure Intrusion of Water and Electrolyte Solutions. New J. Chem. 2017, 41 (24), 15087-15093.

15. Saada, M. A.; Soulard, M.; Marler, B.; Gies, H.; Patarin, J., High-Pressure Water Intrusion Investigation of Pure Silica RUB-41 and S-SOD Zeolite Materialsleng. J. Phys. Chem. C 2011, 115 (2), 425-430. 
16. Tzanis, L.; Trzpit, M.; Soulard, M.; Patarin, J., High Pressure Water Intrusion Investigation of Pure Silica 1D Channel AFI, MTW and TON-type Zeolites. Microporous Mesoporous Mater. 2011, 146 (1-3), 119-126.

17. Tzanis, L.; Trzpit, M.; Soulard, M.; Patarin, J., Energetic Performances of Channel and Cage-Type Zeosils. J. Phys. Chem. C 2012, 116 (38), 20389-20395.

18. Trzpit, M.; Soulard, M.; Patarin, J., The Pure Silica Chabazite: A High Volume Molecular Spring at Low Pressure for Energy Storage. Chem. Lett. 2007, 36 (8), 980-981.

19. Khay, I.; Tzanis, L.; Daou, T. J.; Nouali, H.; Ryzhikov, A.; Patarin, J., Energetic Behavior of the Pure Silica ITQ-12 (ITW) Zeolite Under High Pressure Water Intrusion. Phys. Chem. Chem. Phys. 2013, 15 (46), 2032020325 .

20. Ryzhikov, A.; Khay, I.; Nouali, H.; Daou, T. J.; Patarin, J., Energetic Performances of Pure Silica STF and MTT-type Zeolites Under High Pressure Water Intrusion. Rsc Adv. 2014, 4 (71), 37655-37661.

21. Ronchi, L.; Ryzhikov, A.; Nouali, H.; Daou, T. J.; Albrecht, S.; Patarin, J., Investigation of the Energetic Performance of Pure Silica BEC-type Zeolite Under High Pressure Water and $20 \mathrm{M} \mathrm{LiCl}$ Intrusion-Extrusion Experiments. Microporous and Mesoporous Mater. 2017, 254, 153-159.

22. Ronchi, L.; Ryzhikov, A.; Nouali, H.; Daou, T. J.; Albrecht, S.; Patarin, J., Extra Large Pore Opening CFI and DON-type Zeosils for Mechanical Energy Storage. Microporous and Mesoporous Mater. 2018, 255, 211219.

23. Ievtushenko, O. V.; Eroshenko, V. A.; Grosu, Y. G.; Nedelec, J. M.; Grolier, J. P. E., Evolution of the Energetic Characteristics of Silicalite-1 plus Water Repulsive Clathrates in a Wide Temperature Range. Phys. Chem. Chem. Phys. 2013, 15 (12), 4451-4457.

24. Fraux, G.; Coudert, F. X.; Boutin, A.; Fuchs, A. H., Forced Intrusion of Water and Aqueous Solutions in Microporous Materials: from Fundamental Thermodynamics to Energy Storage Devices. Chem. Soc. Rev. 2017, 46 (23), 7421-7437.

25. Surani, F. B.; Qiao, Y., Infiltration and Defiltration of an Electrolyte Solution in Nanopores. J. App. Phys. 2006, 100 (3), 034311.

26. Kong, X.; Qiao, Y., Improvement of Recoverability of a Nanoporous Energy Absorption System by Using Chemical Admixture. App. Phys. Lett. 2005, 86 (15), 151919.

27. Soulard, M.; Patarin, J. Process for High-Pressure Energy Storage by Solvation/Desolvation and Associated Storage Device. Patent FR2976030, 2011.

28. Tzanis, L.; Nouali, H.; Daou, T. J.; Soulard, M.; Patarin, J., Influence of the Aqueous Medium on the Energetic Performances of Silicalite-1. Mater. Lett. 2014, 115, 229-232.

29. Khay, I.; Daou, T. J.; Nouali, H.; Ryzhikov, A.; Rigolet, S.; Patarin, J., High Pressure Intrusion-Extrusion of LiCl Aqueous Solutions in Silicalite-1 Zeolite: Influence on Energetic Performances. J. Phys. Chem. C 2014, 118 (8), 3935-3941.

30. Ronchi, L.; Ryzhikov, A.; Nouali, H.; Daou, T. J.; Patarin, J., Influence of LiCl Aqueous Solution Concentration on the Energetic Performances of Pure Silica Chabazite. New J. Che. 2017, 41 (7), 2586-2592. 
31. Ronchi, L.; Ryzhikov, A.; Nouali, H.; Daou, T. J.; Patarin, J., Energetic Performances of Pure-Silica DDR Zeolite by High-Pressure Intrusion-Extrusion of Electrolyte Aqueous Solutions: A Shock-Absorber with Huge Absorbed Energy. J. Phys. Chem. C 2018, 122 (5), 2726-2733.

32. Ryzhikov, A.; Ronchi, L.; Nouali, H.; Daou, T. J.; Paillaud, J. L.; Patarin, J., High-Pressure IntrusionExtrusion of Water and Electrolyte Solutions in Pure-Silica LTA Zeolite. J. Phys. Chem. C 2015, 119 (51), 2831928325.

33. Washburn, E. W., Note on a Method of Determining the Distribution of Pore Sizes in a Porous Materia. Proc. Nat. Acad. Sci. U.S.A. 1921, 7, 115-116.

34. Han, A. J.; Lu, W. Y.; Kim, T.; Chen, X.; Qiao, Y., Influence of Anions on Liquid Infiltration and Defiltration in a Zeolite Y. Phys. Rev. E 2008, 78 (3), 031408.

35. Han, A. J.; Lu, W. Y.; Kim, T. W.; Punyamurtula, V. K.; Qiao, Y., The Dependence of Infiltration Pressure and Volume in Zeolite Y on Potassium Chloride Concentration. Smart Mat. Struct. 2009, 18 (2), 5.

36. Michelin-Jamois, M.; Picard, C.; Vigier, G.; Charlaix, E., Giant Osmotic Pressure in the Forced Wetting of Hydrophobic Nanopores. Phys. Rev. Lett. 2015, 115 (3), 036101.

37. Arletti, R.; Ronchi, L.; Quartieri, S.; Vezzalini, G.; Ryzhikov, A.; Nouali, H.; Daou, T. J.; Patarin, J., Intrusion-Extrusion Experiments of $\mathrm{MgCl}_{2}$ Aqueous Solution in Pure Silica Ferrierite: Evidence of the Nature of Intruded Liquid by in Situ High Pressure Synchrotron X-ray Powder Diffraction. Microporous and Mesoporous Mater. 2016, 235, 253-260.

38. Arletti, R.; Fois, E.; Gigli, L.; Vezzalini, G.; Quartieri, S.; Tabacchi, G., Irreversible Conversion of a WaterEthanol Solution into an Organized Two-Dimensional Network of Alternating Supramolecular Units in a Hydrophobic Zeolite under Pressure. Angew. Chem. Int. Ed. 2017, 56 (8), 2105-2109.

39. Arletti, R.; Fois, E.; Tabacchi, G.; Quartieri, S.; Vezzalini, G., Pressure-Induced Penetration of WaterEthanol Mixtures in All-Silica Ferrierite. Adv. Sci. Lett. 2017, 23 (6), 5966-5969.

40. Arletti, R.; Leardini, L.; Vezzalini, G.; Quartieri, S.; Gigli, L.; Santoro, M.; Haines, J.; Rouquette, J.; Konczewicz, L., Pressure-Induced Penetration of Guest Molecules in High-Silica Zeolites: the Case of Mordenite. Phys. Chem. Chem. Phys. 2015, 17 (37), 24262-24274.

41. Lotti, P.; Arletti, R.; Gatta, G. D.; Quartieri, S.; Vezzalini, G.; Merlini, M.; Dmitriev, V.; Hanfland, M., Compressibility and Crystal-Fluid Interactions in All-Silica Ferrierite at High Pressure. Microporous and Mesoporous Mater. 2015, 218, 42-54.

42. Gigli, L.; Arletti, R.; Tabacchi, G.; Fois, E.; Vitillo, J. G.; Martra, G.; Agostini, G.; Quartieri, S.; Vezzalini, G., Close-Packed Dye Molecules in Zeolite Channels Self-Assemble into Supramolecular Nanoladders. J. Phys. Chem. C 2014, 118 (29), 15732-15743.

43. Leardini, L.; Quartieri, S.; Vezzalini, G., Compressibility of Microporous Materials with CHA Topology: 1. Natural Chabazite and SAPO-34. Microporous and Mesoporous Mater. 2010, 127 (3), 219-227.

44. Diaz-Cabanas, M. J.; Barrett, P. A.; Camblor, M. A., Synthesis and Structure of Pure $\mathrm{SiO}_{2}$ Chabazite: the SiO2 Polymorph with the Lowest Framework Density. Chem. Commun. 1998, (17), 1881-1882. 
45. Miletich, R.; Allan, D.R.; Kuhs, W.F., High Temperature and High-Pressure Crystal Chemistry. Rev.in Mineral. Geochem. Mineralogical Society of America and Geochemical Society Washington, USA, 2000, (41), 445-519.

46. Forman, R.; Piermarini, G.; Barnett, J.; Block, S., Pressure Measurement Made by the Utilization of Ruby Sharp-Line Luminescence. Science 1972, 176 (4032), 284-285.

47. Mao; H. K.; Xu, J.; Bell, P. M., Calibration of the Ruby Pressure Gauge to 800 kbar Under QuasiHydrostatic Conditions. J. Geophys. Res. 1986, 91, 4673.

48. Prescher, C.; Prakapenka, V. B., DIOPTAS: a Program for Reduction of Two-Dimensional X-ray Diffraction Data and Data Exploration. High Pressure Res. 2015, 35 (3), 223-230.

49. Larson; A. C.; Von Dreele, R. B., General Structure Analysis System "GSAS"; Los Alamos National Laboratory Report; Los Alamos, 1994; LAUR 86-748.

50. Toby, B. H., EXPGUI, A Graphical User Interface for GSAS. J. App. Cryst. 2001, 34, 210-213.

51. Thompson, P.; Cox, D. E.; Hastings, J. B., Rietveld Refinement of Debye-Scherrer Synchrotron X-Ray Data from $\mathrm{Al}_{2} \mathrm{O}_{3}$. J. App. Cryst. 1987, 20, 79-83.

52. Baerlocher, Ch.; McCusker, M., Database of Zeolite Structures. In http://www.izastructure.org/databases/.

53. Lilov, S. K., Determination of the Effective Kinetic Diameter of the Complex-Molecules. Cryst. Res. Technol. 1986, 21 (10), 1299-1302.

54. Ryzhikov, A.; Nouali, H.; Daou, T. J.; Patarin, J., A Drastic Influence of the Anion Nature and Concentration on High Pressure Intrusion-Extrusion of Electrolyte Solutions in Silicalite-1. Phys. Chem. Chem. Phys. 2018, 20 (9), 6462-6468. 